\title{
Investigation of microhardness evolution in an ultrafine grained NiTi alloy formed via high speed high pressure torsion (HSHPT)
}

\author{
Gheorghe Gurau ${ }^{1}$, Carmela Gurau ${ }^{1, a}$ and V Sampath ${ }^{2}$ \\ ${ }^{1}$ Faculty of Engineering "Dunarea de jos" University of Galati, Domneasca Street, No. 111, 800201, Galati, Romania \\ ${ }^{2}$ Department of Metallurgical and Materials Engineering, Indian Institute of Technology Madras, Chennai-600 036, India
}

\begin{abstract}
An investigation was conducted so as to evaluate the homogeneity of microstructure and mechanical properties of an NiTi shape memory alloy subjected to high speed high pressure torsion (HSHPT). The alloy chosen for the study had 50.3 at.\% of $\mathrm{Ni}$ in its composition and was supplied in the form of hot extruded rods of $9 \mathrm{~mm}$ diameter. The final shape achieved after severe plastic deformation was a disc, whose diameter and thickness measured $40 \mathrm{~mm}$ and $0.18 \mathrm{~mm}$, respectively. The TEM studies and the microhardness determination using a Vickers hardness tester revealed the effect of dynamic recrystallisation, which is very unique to severe plastic deformation involving HSHPT. An analysis of the microhardness data shows that the disc-shaped element is essentially homogeneous. In addition, the microhardness increases with the increase in accumulated strain. The results are presented and discussed in detail in the paper..
\end{abstract}

\section{Introduction}

Ni-Ti based alloys have been attractive functional materials as commercial shape memory alloys (SMAs) owing to their high strength and ductility, corrosion resistance, excellent fatigue resistance and biocompatibility [1-4]. Because of its capability to produce nanocrystalline and submicrocrystalline bulk materials, severe plastic deformation (SPD) represents one of the ways by which the properties of Ni-Ti shape memory alloys [5] can be improved. It is well known that the functional characteristics of Ni-Ti SMAs are highly sensitive to their microstructure, especially to grain size reduction [6-10].

High pressure torsion (HPT) represents one of the more frequently used and attractive SPD methods to improve the functional properties of pure metals and alloys [11-14]. High speed high pressure torsion (HSHPT) is a new technique that evolved from classical HPT and refers to the processing of metals by subjecting them to simultaneous application of high compressive pressure and torsion. The major difference between the two methods lies in the introduction of torsion by high rotational speed of the upper anvil $[15,16]$.

The present paper describes the influence of the degree of deformation imposed by the HSHPT severe plastic processing on the development of microstructure (substructure) and mechanical properties of an $\mathrm{Ni}-\mathrm{Ti}$ shape memory alloy.

\section{Materials and methods}

\footnotetext{
${ }^{a}$ Corresponding author: carmela.gurau@ugal.ro
}

The alloy Ni50.3-Ti (at \%) was selected for the study. The as-received Ni-rich alloy was in the form of hot extruded rods of $9 \mathrm{~mm}$ in diameter $(\Phi)$. For the present work an indigenously built HSHPT equipment was used. The design of the machine is dealt with in detail in one of our earlier papers [15]. The HSHPT parameters were monitored using an EATON SVX024A1-4A1B1 frequency converter via PLC XC 200. The rotational speed of the upper anvil was selected at $1795 \mathrm{rpm}$. The pressure level, recorded with a Hottinger Spider 8 equipment, was at $2.03 \mathrm{GPa}$. The maximum torsional moment was $60.7 \mathrm{Nm}$. Specimens cut from the extruded wires were HSHPT processed. The material was subjected to strain levels between 1.12 and 2.81. The SPD discs were obtained after giving different amounts/degrees of deformation achieving up to $40 \mathrm{~mm}$ in diameter and between $1.51 \mathrm{~mm}$ and $0.18 \mathrm{~mm}$ in thickness. The extent of deformation strain was estimated using the logarithmic relationship given in [11].

The specimens cut from the discs subjected to HSHPT processing to varied levels of deformation, were prepared for microstructural examinations by scanning electron microscopy (SEM) as well as transmission electron microscopy (TEM). The samples diametrically cut and embedded into cold mounting resin were prepared adopting standard metallographic practice followed by etching using a solution of 10 vol. $\%$ of $\mathrm{HF}+45$ vol. $\%$ of $\mathrm{HNO}_{3}+45$ vol. $\%$ of $\mathrm{H}_{2} \mathrm{O}$. A Zeiss microscope equipped with an energy dispersive $\mathrm{X}$-ray spectroscope was used for the SEM observation. The microstructural analysis of the samples by TEM was carried out using a Tecnai $20 \mathrm{G} 2$ TEM equipped with EDX facility operating at a voltage 
of $200 \mathrm{kV}$. Thin foils were prepared using an electrolyte with $90 \%$ by vol. of methanol and $10 \%$ by vol. of perchloric acid. The phase identification was carried out using an X-ray diffractometer (Bruker AXS D8 Discover) using $\mathrm{Cu}-\mathrm{K} \alpha$ radiation at room temperature in the scanning range $(2 \theta)$ of $20^{\circ}-90^{\circ}$. Room temperature Vickers microhardness values were determined using an indenter under a load of $0.98067 \mathrm{~N}\left(\mathrm{HV}_{0.1}\right)$ applied for $10 \mathrm{~s}$.

\section{Results and discussion}

The high speed high pressure torsion (HSHPT) is a severe plastic deformation method based on the wellknown high pressure torsion (HPT) technique. In HPT process, the sample is pressed (1 to $10 \mathrm{GPa})$, while at the same time subjected to torsion (1-10 rpm, 10-100 Nm) [11]. The torsion flows without slippage between sample and rotating anvil, i.e., this slippage is very limited and strictly controlled. In this case, the heat generation occurs due to internal friction. The HPT process has a limitation on the sample dimensions (usually $\sim 10 \mathrm{~mm}$ in diameter), and the shape of the sample (only disc and ring shapes may be achieved).

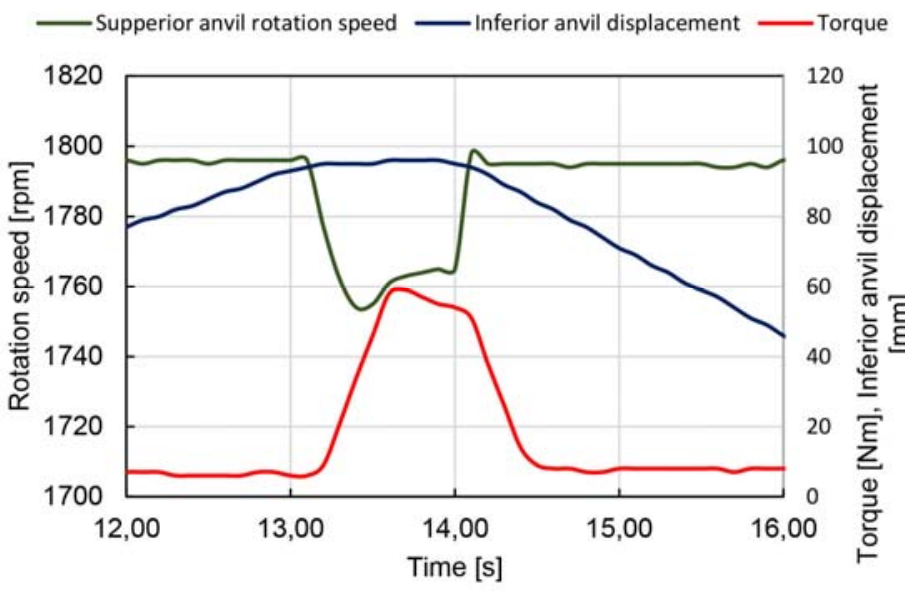

Figure 1. Plots of HSHPT parameters versus time

Most importantly, the plasticity of the sample restrains the HPT applicability $[18,19]$. In addition, the transformation is suppressed in amorphous regions or in

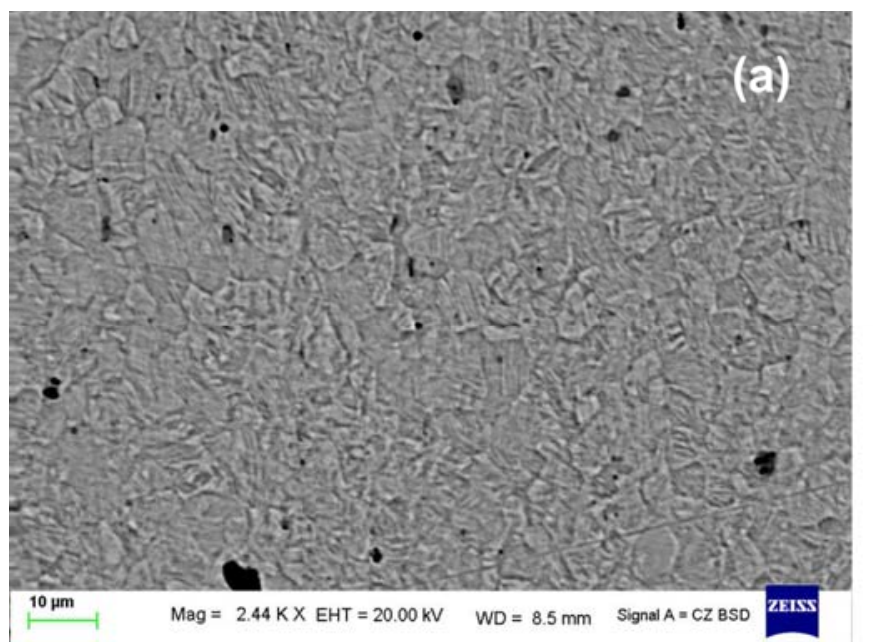

areas containing nanocrystals in shape memory alloys. This necessitates post-deformation annealing (PDA) [20, 21].

The HSHPT technique helps overcome this limitation. In other words, the HSHPT process is very similar to HPT in terms of pressure and torsion. But considering the rotational speed of the upper piston, it is vastly different from it (falling in the range of thousands of rpm). As is shown in Fig. 1 the rotational speed may be around 1800 $\mathrm{rpm}$. This simple modification in HPT process determines the largest slippage at the sample-anvil interface. The differences between HPT and HSHPT can be emphasized. First, the friction between the sample and the anvil under high pressure conditions causes a large amount of heat. The sample is heated at a high heating rate (hundreds of ${ }^{0} \mathrm{C} / \mathrm{s}$ ) starting from room temperature to the temperature at which hot deformation process (800$900{ }^{\circ} \mathrm{C}$ ) is carried out. It is thus obvious the advantages of the high temperature SPD. The main advantage is the increase in plasticity. A number of alloys that cannot be processed by SPD owing to their low plasticity (such as $\mathrm{Cu}-\mathrm{Al}-\mathrm{Ni}$ SMAs in the cast condition) are amenable to processing via HSHPT. Hot SPD allows to obtain complex shapes with rotational symmetry, such as a cone. In addition, the dimensions of objects produced by HSHPT are at least four times those produced by HPT (i.e., surface, diameter). In the context of shape memory alloys, HSHPT process helps obtain ultrafine grains without the need for PDA treatments. As is shown in Fig. 1 , the entire SPD process for this NiTi alloy occurs in one second from the time the superior anvil makes a contact with the sample to the time when the sample is withdrawn. This extremely short span of time involved in the processing explains the formation of a fine structure with very limited recrystallization. It should be mentioned that the HSHPT process starts at a temperature when the anvil and the sample are around $25^{\circ} \mathrm{C}$.

The very high strain rate arises due to a large contact area that the severely hot deformed sample makes with the cold anvils, leading to high heat transfer rates.

These observations together with the following investigations led us to affirm that the fine (ultrafine) structure achieved by HSHPT remains unaltered till the very end of the process. Fig.2 micrographs are intended to illustrate the changes the fully austenitic hot-rolled

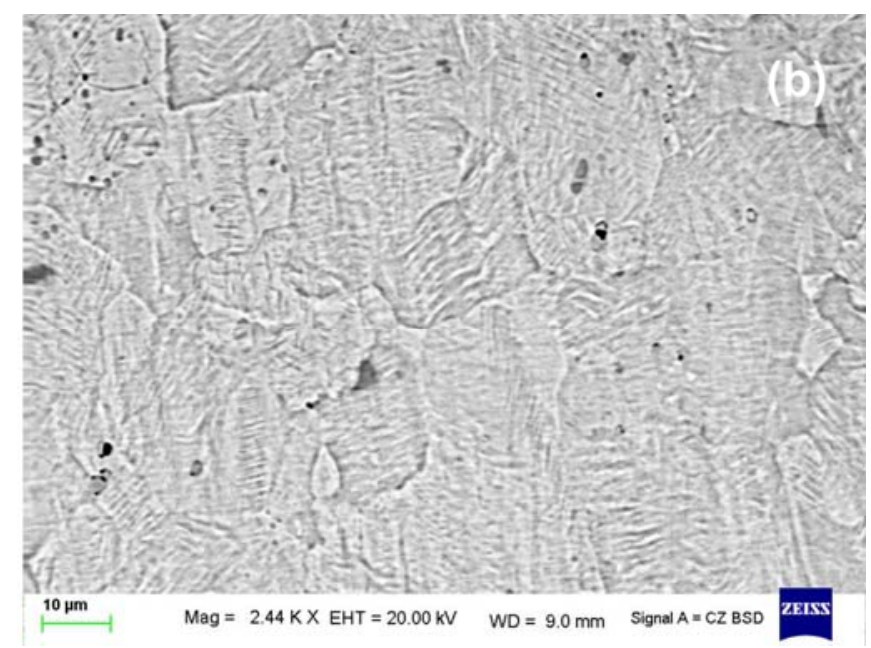

Figure 2. Secondary images of NiTi alloy after severe plastic deformation by HSHPT to: a. logarithmic strain of 1.37; b. logarithmic strain of 1.12 
NiTi alloy brought about by the concurrent action of the compressive and torsional forces introduced during processing by HSHPT.

After subjecting the alloy to the HSHPT processing to a logarithmic strain of 1.12, the grains exhibit apparent grinding. This leads to the proliferation of substructural features within the B2 austenite grains, especially randomly oriented twins (Fig.2(b)).

The refinement of the grain size is more evident after increasing degree of deformation as shown in Fig.2(a). The tendency for agglomeration of secondary phase particles can be noticed.

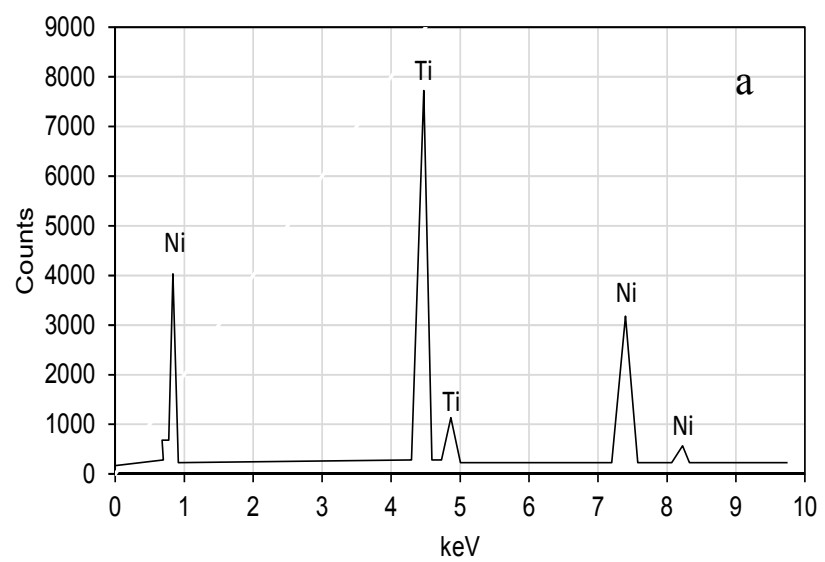

strain of 1.38 and 2.81, respectively, are illustrated in Fig.4. The NiTi samples are mainly composed of B2 (austenite), B19' (martensite) and small amount of precipitate particles as evident from the diffractograms. By increasing the degree of deformation the peak intensity declines while at the same time it leads to peak broadening. This could be attributed to the refinement of crystallite size and enhancement of dislocation density of the alloy [24].

For a deeper evaluation of the submicrostructure, the HSHPT specimens were examined in detail by transmission electron microscopy. Figure 5 shows the

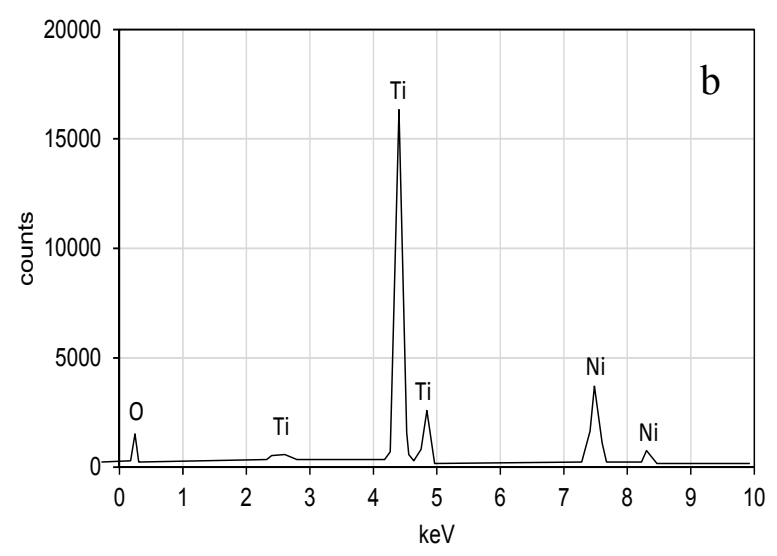

Figure 3. EDX spectra for (a) the matrix and (b) the secondary phase.

Fig.3 shows the EDX spectra of B2 matrix (a) and precipitate (b), respectively. The results bring out the difference in the relative amounts of $\mathrm{Ni}$ and $\mathrm{Ti}$ in the matrix and the second phase, respectively. For the alloy composition studied it was expected that the precipitate particles would become richer in $\mathrm{Ni}$ due to the depletion of the matrix of Ni $[22,23]$. On the contrary, the second phase became rich in $\mathrm{Ti}$ and poor in $\mathrm{Ni}$. The second phase underwent agglomeration to form larger precipitate particles in comparison with the other alloy systems processed via HSHPT.

In order to investigate the structural evolution taking place after severe plastic deformation via HSHPT, the XRD curves of the samples subjected to a logarithmic bright field TEM micrographs of the NiTi sample that was subjected to a deformation level of 1.63. Figure 5 [(a) and (b)] presents the heavily deformed microstructure showing a complex strain contrast with appearance of many twins (T), lattice defects (dislocation accumulated in clusters, dislocation tangles (DT), high density of dislocations (DHD)) and residual stress field.

Fig.5(c) highlights multiple fine twins and variants with random orientations as can be seen clearly in the enlarged TEM micrograph. It can be noticed that in all TEM micrographs the variants have no preferred orientation. Fig.5(d) shows the twin structure of the alloy. Since B19' (martensite) forms with a monoclinic crystal structure, low symmetry with several twinning modes is expected.

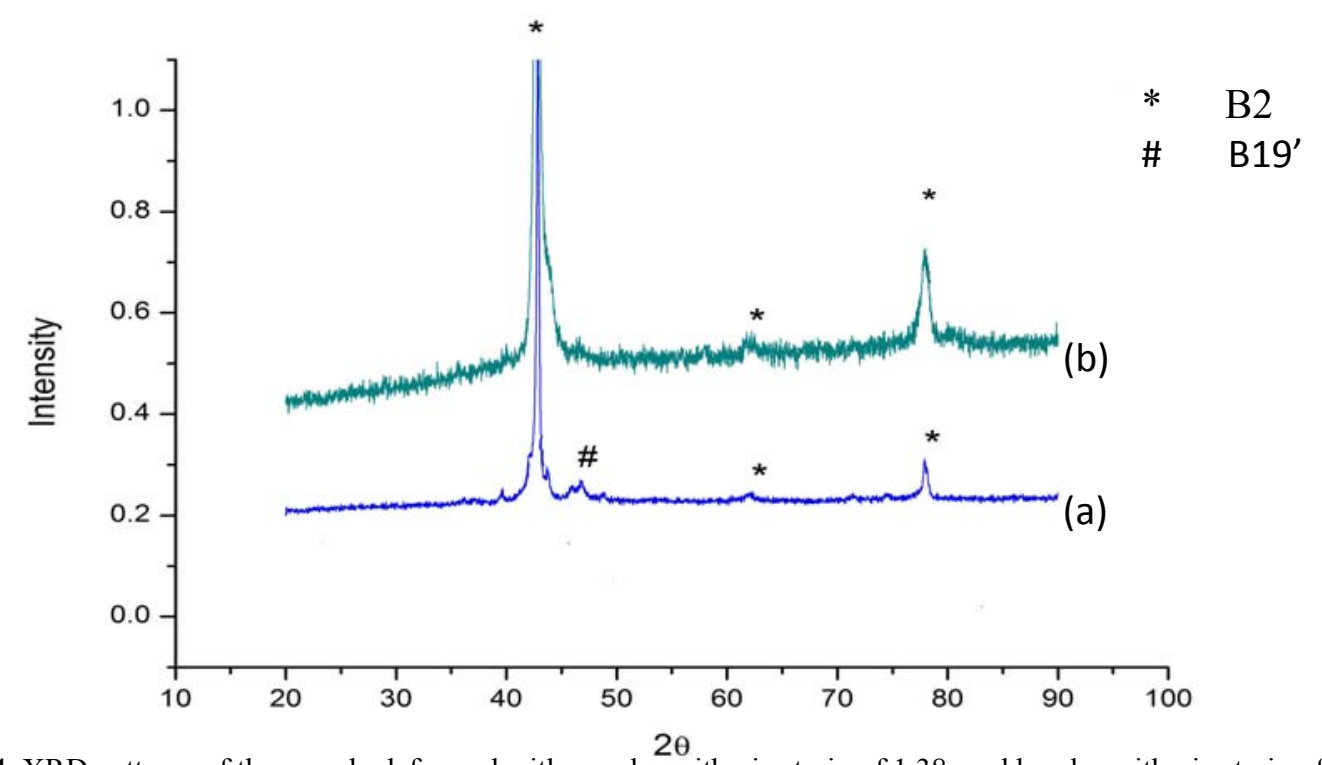

Figure 4. XRD patterns of the sample deformed with: a. a logarithmic strain of 1.38; and b. a logarithmic strain of 2.81 . 
But the most frequently observed twinning system is $<011>$ m Type II $[1,2]$. The structure outlines very fine twins with their size in the range of 20-50 nm. The presence of high dislocation density can be found within the curved grain boundaries with a dark area contrast. responsible for the development of novel, significantly better properties as compared to those from their coarse grained counterparts. The grain boundary features created by SPD depends on the technological parameters of processing (pressure, torque, degree of deformation and
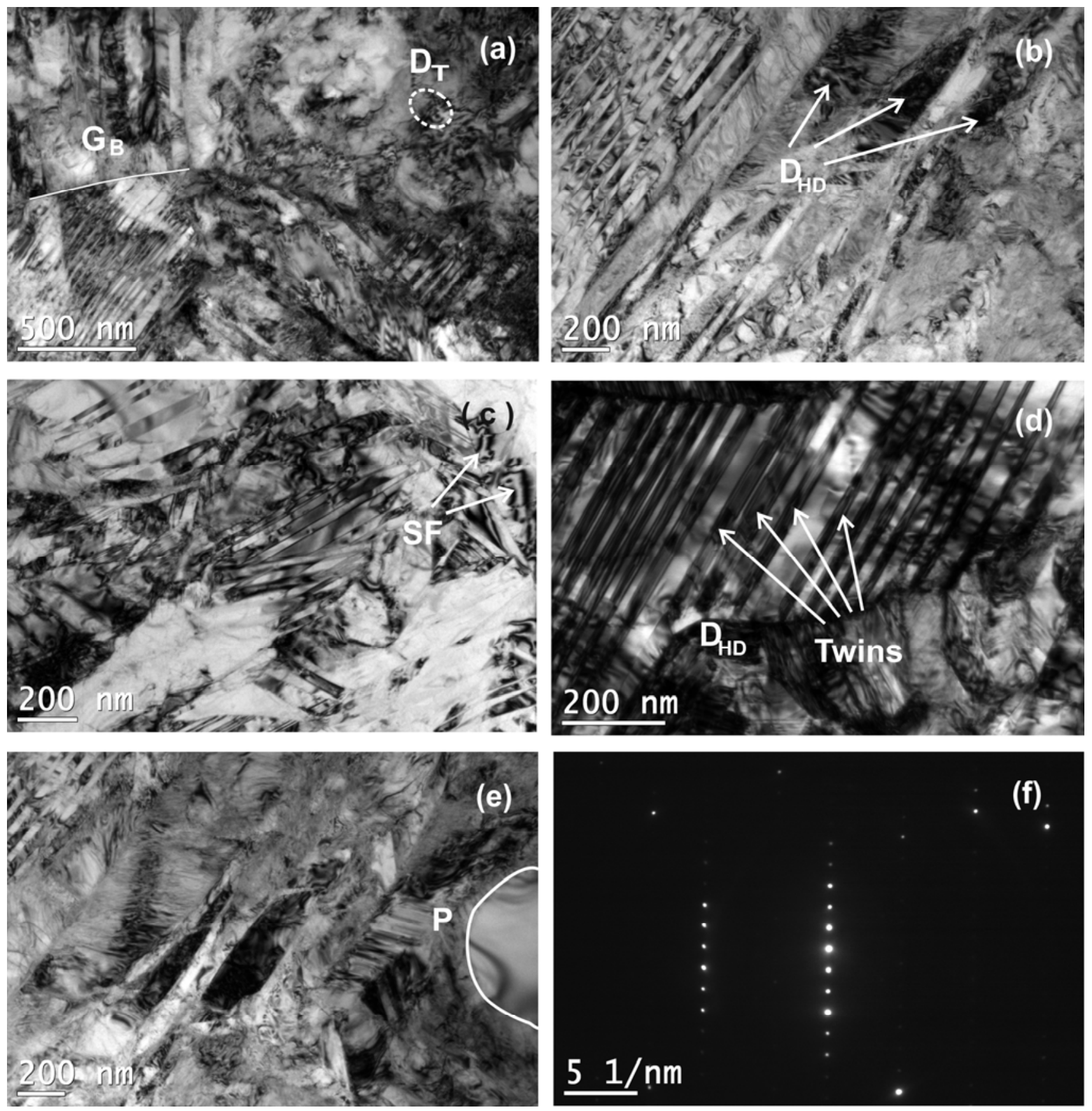

Figure 5. TEM of the NiTi severe plastic deformed by HSHPT: logarithmic strain 1.63 (a-e) and (f) the corresponding diffraction area from (e).

Figures 5 (e) shows a distorted structure in close proximity to a large coagulated precipitate, while Figure 5 (f) shows the corresponding diffraction.

It is this fine structure that is responsible for the growing hardness of the alloy. Ultrafine grained materials in their microstructure contain a very high volume fraction of grain boundaries, which may largely be temperature) [25]. The small compositional fluctuations along GBs, especially those along the grain boundary twins, may predetermine the mechanical behaviour of bulk UFG Ni-Ti alloy.

In the case of samples processed by HSHPT, the high temperature developed in the sample by internal 
friction and slippage during severe plastic deformation plays an important role.

The hardness values of the as-received and HSHPTprocessed specimens are presented in Fig.6. The microhardness data were taken along the cross section of specimen with a linear increment of $1 \mathrm{~mm}$ along the diameter, from the centre to the edge of the specimen.

The hardness of the coarse-grained initial sample $(0$ logarithmic strain) was approximately $223 \mathrm{HV}$. Increasing the degree of deformation leads to an increase in hardness. It should be noted that a low strain (logarithmic strain 1.3) imparted by HSHPT method presents the same unevenness in hardness values between the center $(268 \mathrm{HV})$ and the edge $(437 \mathrm{HV})$ of the disc as compared to the results obtained from processing by the classic HPT process. In classic HPT processing of materials, where dynamic recovery occurs at a slower rate, the hardness is lower at the center in the initial stages of torsional straining [11]. This is more pronounced when the discs are thinner. When applying higher degrees of deformation, the variation of average microhardness along the diameter is much smoother. An analysis of the microhardness data shows that the discshaped elements are essentially homogeneous. The difference in values of hardness from the center to the edge of specimens is up to $30 \mathrm{HV}$. The corrugated aspect of curves is expected in Ni-rich Ni-Ti alloy in which coarse second phase particles occur during agglomeration process. The Vickers microhardness values are fairly consistent with optical and TEM observations discussed earlier (Fig.2 and Fig.5).

Comparing the results of the microhardness of the ultrafine grained Ni-Ti alloy obtained by HSHPT with those from the existing literature after other SPD methods, a decreasing tendency can be observed. In our study, it was also observed that the microhardness values are similar to those observed from grain-refined alloy resulting from the HPT followed by PDA process [2628]. Shahmir et al. acquired very similar range of Vickers microhardness values after quasi-constrained HPT through 10 turns and PDA $10 \mathrm{~min}$ at $400^{\circ} \mathrm{C}$ [29]. It is common practice to apply PDA after severe plastic deformation in order to decrease internal stress and partially recover dislocation substructure that acts as barriers to the phase displacement. However, the treatment is no longer required because these microstructural changes are already taking place within the material during the HSHPT process.

\section{Conclusions}

SPD processing by HSHPT technique leads to the occurrence of significant grain refinement down to the nanocrystalline range in a nickel-rich shape memory alloy.

HSHPT is a promising method for achieving Ni-Ti semi-products with rotational symmetry, whose

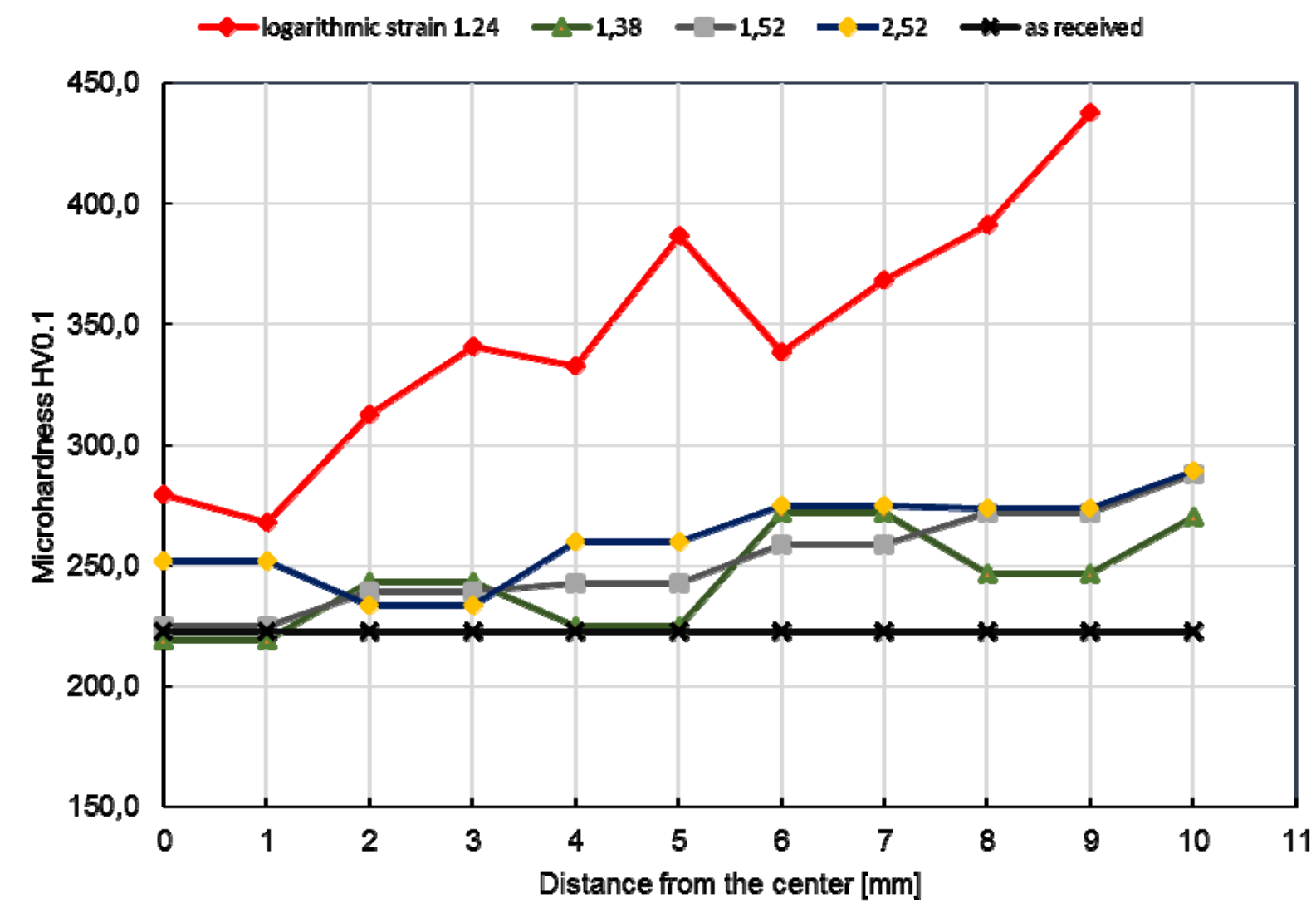

Figure 6. Microhardness profile along the sample diameter 
dimensions exceed those of the HPT samples by four times (i.e. surface, diameter). The HSHPT technique is a ones-step SPD process that combines high hydrostatic pressure and torsional straining with PDA treatments at low temperature. The ultrafine grain structure obtained by severe deformation can be retained without leading to amorphization.

The hardness of HSHPT processed specimens slightly increased with increasing of the deformation degree, being essentially homogeneous along diameter.

\section{Acknowledgements}

This research work was supported by the Project PN.IIPT-PCCA-2011-3.1-0174, Contract 144/2012. We would like to gratefully acknowledge the help rendered by Department of Metallurgical and Materials Engineering, Indian Institute of Technology Madras, Chennai in the investigations.

\section{References}

1. K. Otsuka, X. Ren, Progr. Mat. Sci. 50, 511 (2005)

2. K.Tsuchiya, M. Inuzuka, D. Tomus, A. Hosokawa, H. Nakayama, K. Morii, Y. Tokada, M. Umemoto, Mat.Sci.Eng. A438-440, 643 (2006)

3. X. Wang, B. Verlinden, J.V. Humbeeck, Intermet. 62, 43 (2015)

4. K.C. Atli, I. Karaman, R.D. Noebe, A. Garg, Y.I. Chumlyakov, I.V. Kireeva, Acta Mat. 59, 4747 (2011)

5. K. Tsuchiya, M. Inuzuca, D. Tomus, A. Hosokawa, H. Nakayama, K. Morii, Y. Todaka, M. Umemoto, Mat.Sci.Eng. A438, 643 (2006)

6. R. Kocich, M. Kursa, I. Szurman, A. Dlouhi, J.Al.Com. 509, 2716 (2011)

7. E. Schaefler, M.B. Kerber, Mat.Sci.Eng. A462, 139 (2007)

8. S.C. Mao, H.X. Li, Y. Liu, Q.S. Deng, L.H. Wang, Y.F. Zhang, Z. Zhang, X.D. Han, J.Al.Com. 579, 100 (2013)
9. B. Kockar, I. Karaman, A. Kulkarni, Y. Chumlyakov, I.V. Kireeva, J. Nuclear Mat., 361, 298-305, (2007)

10. X. Wang, S. Kustov, K.Li, D. Schryvers, B. Verlinden, Acta Mat. 82, 224 (2015)

11. A. P. Zhilyaev, T. G. Langdon, Progr.Mat. Sci. 53, 893 (2008)

12. M.J. Starink, X. Cheng, S. Yang, Acta Mat. 61, 183 (2013)

13. S. Jiang, Y Zhang, L. Zhao, Y. Zheng, Intermet. 32, 344 (2013)

14. R. Vafaei, M.R. Toroghinejad, R. Pippan, Mat.Sci.Eng. A536, 73 (2012)

15. G. Gurău, C. Gurău, O. Potecașu, P. Alexandru, L.G. Bujoreanu, J. Mater. Eng. Perform. 23, 2396 (2014)

16. S. Bayramoglu, C. Hacan Gur, I.V. Alexandrov, M.M. Abramova, Mat.Sci.Eng. A 527, 927 (2010)

17. K.K. Mahesh, F.M. Braz Fernandes, G. Gurau, J. Mater. Sci. 47,6005 (2012)

18. A. Kreitchberg, V. Brailovski, S. Prokoshkin, D. Gunderov, M. Khomutov, K. Inaekyan, Mat Sci. Eng. A 622, 21-29, (2015)

19. Y. Harai, K. Edalti, Z. Horita, T.G. Langdon, Acta Mat. 57, 1147 (2009)

20. T. Waitz, Acta Mater. 53, 2273 (2005)

21. D. Vojtech, A. Michalcova, J Capek, I Marek, L. Dragounova, Intermet. 49, 7 (2014)

22. Z. Yang, W. Tirry, D. Shryers, Scripta Mat. 52, 1129 (2005)

23. A. Evirgen, I. Karaman, R. Santamarta, J. Pons, R.D. Noebe, Acta Mat. 83, 48 (2015)

24. E. Mohamad Sharifi, A. Kermanpur, F. Karimanzadeh, Mat. Sci. Eng. A 598, 183 (2014)

25. X. Sauvage, G. Wilde, S.V. Divinski. Z. Horita, R.Z. Valiev, Mat. Sci. Eng. A540, 1 (2012)

26. M. Karimazadeh, M.R. Aboutalebi, M.T. Salehi, S.M. Abbasi, M. Morakabati, J. All. Com. 637, 171 (2015)

27. A.R. Pelton, J. DiCello, S. Miyazaki, Minim. Invas. Ther. Allied.Technol 9, 107 (2000)

28. A.K. Srivastava, D. Schryvers, J.Van Humbeeck, Intermet.15, 1538 (2007)

29. H. Shahmir, M. Nili-Ahmadabadi, Y. Huang, J. Myun Jung, Mat. Sci. Eng. A626, 203 (2015) 